\title{
Metformin exerts glucose-lowering action in high-fat fed mice via attenuating endotoxemia and enhancing insulin signaling
}

\author{
Zi-yu ZHOU, Li-wei REN, Ping ZHAN, Han-yan YANG, Dan-dan CHAl, Zhi-wen YU* \\ Fujian Key Laboratory of Chinese Materia Medica, Biomedical Drug R\&D Center, Fujian University of Traditional Chinese Medicine, \\ Fuzhou 350122, China
}

\begin{abstract}
Aim: Accumulating evidence shows that lipopolysaccharides (LPS) derived from gut gram-negative bacteria can be absorbed, leading to endotoxemia that triggers systemic inflammation and insulin resistance. In this study we examined whether metformin attenuated endotoxemia, thus improving insulin signaling in high-fat diet fed mice.

Methods: Mice were fed a high-fat diet for 18 weeks to induce insulin resistance. One group of the mice was treated with oral metformin $\left(100 \mathrm{mg} \cdot \mathrm{kg}^{-1} \cdot \mathrm{d}^{-1}\right)$ for 4 weeks. Another group was treated with LPS $\left(50 \mu \mathrm{g} \cdot \mathrm{kg}^{-1} \cdot \mathrm{d}^{-1}, \mathrm{sc}\right)$ for 5 days followed by the oral metformin for $10 \mathrm{~d}$. Other two groups received a combination of antibiotics for $7 \mathrm{~d}$ or a combination of antibiotics for $7 \mathrm{~d}$ followed by the oral metformin for 4 weeks, respectively. Glucose metabolism and insulin signaling in liver and muscle were evaluated, the abundance of gut bacteria, gut permeability and serum LPS levels were measured.

Results: In high-fat fed mice, metformin restored the tight junction protein occludin-1 levels in gut, reversed the elevated gut permeability and serum LPS levels, and increased the abundance of beneficial bacteria Lactobacillus and Akkermansia muciniphila. Metformin also increased PKB Ser473 and AMPK T172 phosphorylation, decreased MDA contents and redox-sensitive PTEN protein levels, activated the anti-oxidative Nrf2 system, and increased IkB $\alpha$ in liver and muscle of the mice. Treatment with exogenous LPS abolished the beneficial effects of metformin on glucose metabolism, insulin signaling and oxidative stress in liver and muscle of the mice. Treatment with antibiotics alone produced similar effects as metformin did. Furthermore, the beneficial effects of antibiotics were addictive to those of metformin.

Conclusion: Metformin administration attenuates endotoxemia and enhances insulin signaling in high-fat fed mice, which contributes to its anti-diabetic effects.
\end{abstract}

Keywords: metformin; diabetes; high-fat fed mice; gut microbiota; LPS; endotoxemia; AMPK; PTEN; Nrf2

Acta Pharmacologica Sinica (2016) 37: 1063-1075; doi: 10.1038/aps.2016.21; published online 16 May 2016

\section{Introduction}

Insulin resistance is a fundamental pathophysiological mechanism underlying obesity and diabetes ${ }^{[1]}$. Several etiological factors have been proposed as causes of insulin resistance. Chronic low-grade inflammation has been found in relation to insulin-resistant conditions, and it impairs insulin signaling and action. It is increasingly appreciated that the gut microbiota participates in the homeostasis of the host in terms of immunity and energy metabolism ${ }^{[2,3]}$. Recently, gut microbiota has been recognized to be related to the development of obesity and the incidence of type 2 diabetes ${ }^{[3,4]}$. Altering the bacterial composition of the gut can affect multiple aspects related to energy homeostasis, including nutrient absorption

\footnotetext{
${ }^{*}$ To whom correspondence should be addressed.

E-mail yuzhiwen@yahoo.com

Received 2016-01-25 Accepted 2016-03-08
}

and the secretion of gut-derived hormones, such as glucagonlike peptide (GLP-1) ${ }^{[5]}$. In particular, the lipopolysaccharides (LPS) derived from gram-negative bacteria, which are a major component of the outer membrane of these bacteria, can be absorbed intestinally, leading to endotoxemia-triggered systemic inflammation and insulin resistance ${ }^{[3,6]}$. LPS-evoked inflammation is mediated by LPS binding to the Toll-like receptors (TLRs) located in the plasma membranes of various cell types. The activation of TLR- 4 by LPS can activate the major inflammatory signaling protein nuclear factor kappa B (NF-kB), which promotes an inflammatory response $\mathrm{e}^{[6]}$.

Oxidative stress is another important causal factor of insulin resistance $^{[7]}$. Either reactive oxygen species (ROS) overproduction or an impaired capacity to eliminate ROS can cause oxidative stress. In this regard, the function of the master redox regulator, nuclear factor erythroid-derived 2-like 2 (Nrf2) is important in combating oxidative stress ${ }^{[8]}$. Nrf2 is activated by 
Nrf2 translocation from the cytoplasm to the nucleus, where it promotes the expression of a series of anti-oxidative enzymes, including a specifically regulated-protein, NADPH:quinone oxidoreductase- 1 (NQO-1) ${ }^{[8]}$. We have previously observed a marked impairment of the Nrf2 system in mice fed a high-fat diet $(\mathrm{HFD})^{[9,10]}$ and that correcting defective Nrf2 function via supplementation with the chemical Nrf2 activator oltipraz not only attenuated oxidative stress but also improved insulin signaling and glucose metabolism ${ }^{[10]}$. Other synthetic chemical Nrf2 activators and natural Nrf2-activating compounds have also been shown to be effective in improving insulin action and glucose metabolism in various insulin-resistant models ${ }^{19,}$ ${ }^{11-13]}$. In addition, there is probably an interaction between oxidative stress and inflammatory activation. Therefore, Nrf2 may regulate redox balance through inhibiting inflammation, which would contribute to its enhancement of insulin sensitivity.

For over half century, metformin has been used as a firstline anti-diabetic drug, and it is currently taken by 100 million people around the world, but its therapeutic mechanisms are not fully understood. Interestingly, recent studies indicate that the modulatory effect of metformin on the gut microbiota is related to its anti-inflammatory and anti-obesity as well as its therapeutic efficacy on glucose metabolism ${ }^{[14-16]}$. For example, feeding a HFD to mice leads to a reduction in the probiotic Akkermansia muciniphila (A muciniphila) in the gut, which is important in maintaining the integrity of the gut barrier and insulin sensitivity ${ }^{[16]}$, while metformin has recently been shown to reverse this reduction ${ }^{[14-16]}$. Because increased gut permeability has been reported in HFD-fed mice, which can enhance gut bacteria-derived LPS absorption and lead to endotoxemia ${ }^{[17,18]}$, we proposed that metformin could protect gut-barrier function through reversing abnormal alterations of the gut microbiota and, therefore, reduce LPS-induced inflammation and its detrimental effects on insulin action.

In this study, we directly measured gut permeability and blood LPS levels in HFD-fed mice following metformin administration. To further study the impact of metformin in modulating endotoxemia and its effects on insulin signaling and glucose metabolism, LPS injections and antibiotic treatments were applied to the mice, and the molecular alterations relevant to the therapeutic actions of metformin were analyzed.

\section{Materials and methods}

\section{Animal care and treatment}

Male C57BL/6J mice (8 weeks of age), low-fat diet (LFD, D12450B, 10\% calories from fat) and high-fat diet (HFD, D12492, 60\% calories from fat) were purchased from Guangdong Animal Center (Guangzhou, China). The diet formulae are listed in Table 1. The animal experiments were performed in accordance with the Guide for Care and Use of Experimental Animals (Fujian University of Traditional Chinese Medicine). All experimental protocols were approved by the Ethics Committee of the Fujian University of Traditional Chinese Medicine. Mice were housed in an environmentally
Table 1. Diet composition.

\begin{tabular}{|c|c|c|c|c|c|c|}
\hline \multirow[t]{2}{*}{ Products } & \multicolumn{2}{|c|}{ D12450B } & \multicolumn{2}{|c|}{ D12451 } & \multicolumn{2}{|c|}{ D12492 } \\
\hline & gm\% & kcal\% & gm\% & kcal\% & gm\% & kcal\% \\
\hline Protein & 19.20 & 20.00 & 24.00 & 20.00 & 26.20 & 20.00 \\
\hline Carbohydrate & 67.30 & 70.00 & 41.00 & 35.00 & 26.30 & 20.00 \\
\hline Fat & 4.30 & 10.00 & 24.00 & 45.00 & 34.90 & 60.00 \\
\hline Total & \multirow{2}{*}{\multicolumn{2}{|c|}{100}} & & 100 & & 100 \\
\hline kcal/gm & & & 4.73 & & \multicolumn{2}{|l|}{5.24} \\
\hline Ingredient & & gm & & kcal & gm & kcal \\
\hline \multicolumn{2}{|l|}{ Casein, 80 Mesh } & \multicolumn{2}{|c|}{200} & 800 & 200 & 800 \\
\hline \multicolumn{2}{|l|}{ L-Cystine } & \multicolumn{2}{|c|}{3} & 12 & 3 & 12 \\
\hline \multicolumn{2}{|l|}{ Corn Starch } & \multicolumn{2}{|c|}{315} & 1260 & 0 & 0 \\
\hline \multicolumn{2}{|l|}{ Maltodextrin 10} & \multicolumn{2}{|c|}{35} & 140 & 125 & 500 \\
\hline \multicolumn{2}{|l|}{ Sucrose } & \multicolumn{2}{|c|}{350} & 1400 & 68.8 & 275.2 \\
\hline \multicolumn{2}{|c|}{ Cellulose, BW200 } & \multicolumn{2}{|c|}{50} & 0 & 50 & 0 \\
\hline \multicolumn{2}{|l|}{ Soybean Oil } & \multicolumn{2}{|c|}{25} & 225 & 25 & 225 \\
\hline \multicolumn{2}{|l|}{ Lard } & \multicolumn{2}{|c|}{20} & 180 & 245 & 2205 \\
\hline \multicolumn{2}{|c|}{ DiCalcium Phosphate } & \multicolumn{2}{|c|}{13} & 0 & 13 & 0 \\
\hline \multicolumn{2}{|c|}{ Calcium Carbonate } & \multicolumn{2}{|c|}{5.5} & 0 & 5.5 & 0 \\
\hline \multicolumn{2}{|c|}{ Potassium Citrate, $1 \mathrm{H}_{2} \mathrm{O}$} & \multicolumn{2}{|c|}{16.5} & 0 & 16.5 & 0 \\
\hline \multicolumn{2}{|c|}{ Vitamin Mix V1001 } & \multicolumn{2}{|c|}{10} & 40 & 10 & 40 \\
\hline \multicolumn{2}{|c|}{ Choline Bitartrate } & \multicolumn{2}{|c|}{2} & 0 & 2 & 0 \\
\hline \multicolumn{2}{|c|}{ FD\&C Yellow Dye \#5 } & \multirow{2}{*}{\multicolumn{2}{|c|}{0.05}} & 0 & & \\
\hline FD\&C Blue Dye & & & & & 0.05 & 0 \\
\hline Total & & 105 & 5.05 & 4057 & 773.85 & 4057.2 \\
\hline
\end{tabular}

controlled room kept at $22 \pm 2.0{ }^{\circ} \mathrm{C}$ and $50 \% \pm 5 \%$ humidity with a 12-h: 12-h light/dark cycle. Mice had access to food and water ad libitum. After a one-week adaptive period, mice were randomly divided into two weight-matched groups and were fed with either an LFD or HFD. Body weights were measured weekly.

After an 18-week feeding, HFD-fed mice were further divided into HFD and HFD plus metformin (HM) groups for an additional 4 weeks. Metformin (Bristol-Myers Squibb, Shanghai, China) was added to the drinking water and administered at a dose of $100 \mathrm{mg} \cdot \mathrm{kg}^{-1} \cdot \mathrm{d}^{-1}$. The amount of water consumption was recorded, and water was changed daily. In the LPS (Sigma-Aldrich, Shanghai, China) injection experiments, HFDfed mice were divided into HFD, HFD plus metformin (HM) and HFD plus metformin with LPS (HML) groups. Before giving the mice drinking water with metformin, LPS $(50 \mu \mathrm{g}$. $\mathrm{kg}^{-1} \cdot \mathrm{d}^{-1}$ ) was subcutaneously injected into mice for $5 \mathrm{~d}$, and they were then treated with metformin as described above for an additional $10 \mathrm{~d}$. We also performed these experiments on a 
group of mice treated with a combination of antibiotics (HFD plus antibiotics, HA group), namely, ampicillin, metronidazole and neomycin (Sigma-Aldrich, Shanghai, China) at a dose of $1 \mathrm{~g} / \mathrm{L}$ of each dissolved in their drinking water for $7 \mathrm{~d}$, as reported previously ${ }^{[19]}$. These mice were then treated without (HA) or with metformin (HMA) in their drinking water for 4 weeks, as described above.

\section{Blood sample and tissue collection}

All mice were sacrificed after fasting for $12 \mathrm{~h}$. Blood samples were taken and centrifuged at $4^{\circ} \mathrm{C}$ at $1000 \times g$ for $10 \mathrm{~min}$ to collect the serum. To assess insulin signaling, some mice were intraperitoneally injected with insulin (Novo Nordisk, Beijing, China) at a dose of $0.65 \mathrm{U} / \mathrm{kg}$ and sacrificed $10 \mathrm{~min}$ later. The quadriceps femoris, liver, epididymal fat pads, ileum and colon were rapidly isolated and snap-frozen in liquid nitrogen and then stored at $-80^{\circ} \mathrm{C}$ until further analysis.

\section{Intraperitoneal glucose and pyruvate tolerance tests}

Tolerance tests were performed as previously described ${ }^{[10]}$. Mice were fasted overnight, followed by intraperitoneal glucose $(1.5 \mathrm{~g} / \mathrm{kg})$ or pyruvate $(2 \mathrm{~g} / \mathrm{kg})$ injections. Blood samples from the tail were used for glucose measurements.

Insulin, glucose measurements and HOMA insulin resistance index calculation

After the mice were fasted for $12 \mathrm{~h}$, serum samples were collected. To assess serum insulin levels, an ELISA based method (Shanghai Westang Bio-Tech, Shanghai, China) was used. The method was performed according to the manufacturer's guidelines. Serum glucose levels were determined using a glucose assay kit from Sigma-Aldrich (Saint Louis, USA), following the method provided by the manufacturer. The homeostasis model assessment of the insulin resistance index (HOMA-IR) was calculated as [fasting plasma glucose $(\mathrm{mmol} / \mathrm{L})$ *fasting serum insulin $(\mu \mathrm{IU} / \mathrm{mL})] / 22.5$.

\section{Measurement of blood lipid levels}

Fasting serum levels of total cholesterol (TC), triglycerides (TG) and free fatty acids (FFA) were measured using assay kits (Nanjing Jiancheng, Nanjing, China) following the manufacturer's instructions.

\section{Mitochondrial and nuclear fractionation}

Nuclear and mitochondrial fractionation was performed as previously described ${ }^{[9]}$. Approximately $30 \mathrm{mg}$ of tissue was homogenized in $1 \mathrm{~mL}$ of ice-cold buffer containing 20 mmol/L HEPES (pH 7.4), $250 \mathrm{mmol} / \mathrm{L}$ sucrose, $10 \mathrm{mmol} / \mathrm{L}$ $\mathrm{KCl}, 1.5 \mathrm{mmol} / \mathrm{L} \mathrm{MgCl}_{2}, 1 \mathrm{mmol} / \mathrm{L}$ EDTA, $1 \mathrm{mmol} / \mathrm{L}$ EGTA, $1 \mathrm{mmol} / \mathrm{L}$ dithiothreitol and the protease inhibitors $(2 \mu \mathrm{g} / \mathrm{mL}$ aprotinin, $5 \mu \mathrm{g} / \mathrm{mL}$ leupeptin and $2 \mathrm{mmol} / \mathrm{L}$ phenyl methyl sulphonyl fluoride) (Sigma-Aldrich, Shanghai, China). Following the homogenization procedure, the tissue samples were incubated on ice for $20 \mathrm{~min}$ and then centrifuged at $720 \times g$ at $4{ }^{\circ} \mathrm{C}$ for $5 \mathrm{~min}$. The nuclear pellet was dispersed by the buffer and passed through a 21-G needle 20 times. The samples were then centrifuged again at $720 \times g$ at $4{ }^{\circ} \mathrm{C}$ for 10 min. After removing the supernatant, the nuclear pellet was re-suspended in $50 \mu \mathrm{L}$ of nuclear lysis buffer containing 20 mmol/L Tris (pH 7.5), $137 \mathrm{mmol} / \mathrm{L} \mathrm{NaCl}, 2 \mathrm{mmol} / \mathrm{L}$ EDTA, $1 \mathrm{mmol} / \mathrm{L} \mathrm{CaCl}_{2}, 1 \mathrm{mmol} / \mathrm{L} \mathrm{MgCl}_{2}, 1 \%$ Nonidet P-40 (NP-40), $2 \mathrm{mmol} / \mathrm{L}$ sodium orthovanadate, $10 \mathrm{mmol} / \mathrm{L}$ sodium fluoride, $10 \mathrm{mmol} / \mathrm{L}$ sodium pyrophosphate, $10 \%$ glycerol, $0.1 \%$ sodium dodecyl sulfate (SDS) and the aforementioned protease inhibitors. The nuclear pellets were sonicated for $3 \mathrm{~s}$ and saved for Western blotting. For mitochondrial fractionation, whole cell lysates, after removing the nuclei, were centrifuged at $10000 \times g$ at $4^{\circ} \mathrm{C}$ for $10 \mathrm{~min}$, and the pellet was saved as the mitochondrial fraction and stored at $-80^{\circ} \mathrm{C}$.

\section{MDA assay}

MDA levels were determined using the thiobarbituric acid (TBA) method (Nanjing Jiancheng, Nanjing, China). For tissue MDA assays, approximately $30 \mathrm{mg}$ of tissues or mitochondria extracted from $30 \mathrm{mg}$ tissue were homogenized in $300 \mu \mathrm{L}$ of ice-cold PBS. TBA reactions were performed according to the manufacture's guidelines. Briefly, samples were incubated with TBA and SDS at $95^{\circ} \mathrm{C}$ for $80 \mathrm{~min}$, followed by centrifugation at $4000 \mathrm{r} / \mathrm{min}$ for $10 \mathrm{~min}$. Supernatants were transferred to a 96-well plate, and the absorbance was measured at 532 $\mathrm{nm}$. The protein concentration in the samples was determined using a BCA assay kit (Pierce Bio, Rockford, IL, USA). MDA equivalents are expressed as $\mathrm{nmol} / \mathrm{mg}$ tissue protein.

\section{Cell culture and treatment}

HepG2 cells were purchased from American Type Culture Collection (Manassas, VA, USA). Cells were cultured in Dulbecco's modified Eagle's medium (DMEM, Hyclone, Shanghai, China) supplemented with 10\% fetal bovine serum (FBS, Gibco, Shanghai, China), $100 \mathrm{U} / \mathrm{mL}$ penicillin (Gibco, Shanghai, China) and $100 \mu \mathrm{g} / \mathrm{mL}$ streptomycin (Gibco, Shanghai, China) and maintained at $37^{\circ} \mathrm{C}$ with humidified air and $5 \%$ $\mathrm{CO}_{2}$. Before the experiments, the cells were serum-starved for $16 \mathrm{~h}$ and then treated with the indicated reagents for $24 \mathrm{~h}$. The cells were then washed and stimulated with $100 \mathrm{nmol} / \mathrm{L}$ insulin for $15 \mathrm{~min}$ at $37^{\circ} \mathrm{C}$ and then harvested for protein extraction and western blot analysis.

\section{Tissue protein preparation and Western blotting}

Portions of liver, adipose, muscle, ileum and colon tissue samples were homogenized in ice-cold lysis buffer containing $20 \mathrm{mmol} / \mathrm{L}$ Tris ( $\mathrm{pH} 7.5), 137 \mathrm{mmol} / \mathrm{L} \mathrm{NaCl}, 2 \mathrm{mmol} / \mathrm{L}$ EDTA, $1 \mathrm{mmol} / \mathrm{L} \mathrm{CaCl}_{2}, 1 \mathrm{mmol} / \mathrm{L} \mathrm{MgCl}_{2}, 1 \% \mathrm{NP}-40,2$ $\mathrm{mmol} / \mathrm{L}$ sodium orthovanadate, $10 \mathrm{mmol} / \mathrm{L}$ sodium fluoride, $10 \mathrm{mmol} / \mathrm{L}$ sodium pyrophosphate, $10 \%$ glycerol, $2 \mu \mathrm{g} / \mathrm{mL}$ aprotinin, $5 \mu \mathrm{g} / \mathrm{mL}$ leupeptin and $2 \mathrm{mmol} / \mathrm{L}$ phenyl methyl sulphonyl fluoride. The homogenates were then sonicated under ice cold conditions three times for $20 \mathrm{~s}$ and centrifuged at $12000 \mathrm{r} / \mathrm{min}$ for $10 \mathrm{~min}$ at $4{ }^{\circ} \mathrm{C}$. The supernatant was collected. The protein concentration was determined, and samples with equal amounts of proteins were used for the Western blot analysis. The proteins were heated at $95^{\circ} \mathrm{C}$ for 
5 min in an SDS sample loading buffer and then underwent SDS-PAGE analysis as described below. The cellular proteins were separated via SDS-PAGE $(10 \%)$ and transferred to nitrocellulose membranes (Pall Corporation, Pensacola). Following the transfer, the membranes were incubated for $1.5 \mathrm{~h}$ at room temperature in a buffer containing $25 \mathrm{mmol} / \mathrm{L}$ Tris ( $\mathrm{pH}$ 7.6), $154 \mathrm{mmol} / \mathrm{L} \mathrm{NaCl}, 0.1 \%$ Tween-20 and 5\% skim milk. The membranes were then probed with antibodies overnight at $4^{\circ} \mathrm{C}$. Occludin- 1 , glyceraldehyde-3-phosphate dehydrogenase (GAPDH) and secondary antibodies conjugated to horseradish peroxidase (HRP) were from Santa Cruz Biotechnology (Santa Cruz, CA, USA). Nrf2, IкBa, NQO-1 and heme oxygenase-1 (HO-1) antibodies were from Proteintech Group (Chicago, IL, USA). PKB, PKB Ser473, AMPK, AMPK T172, phosphorylated acetyl-CoA carboxylase Ser89 (p-ACC), phosphorylated eIF2a Ser51, phosphatase tensin-homolog deleted on chromosome ten (PTEN) and histone 3 antibodies were obtained from Cell Signaling Technology (Danvers, MA, USA). After being incubated with the antibodies, the membranes were then washed and incubated with an appropriate secondary HRP-conjugated antibody. Immunoreactive proteins were visualized using enhanced chemiluminescence (Thermo Scientific, Rockford, IL, USA). The intensities of the bands were quantified by phosphorimager analysis using NIH image software.

\section{LPS assay}

Serum LPS levels were quantified using an LPS enzyme-linked immunosorbent assay (ELISA) kit (CUSABIO, Wuhan, China) following the manufacturer's instructions.

\section{Gut permeability assessment}

This experiment was conducted using an oral $D$-xylose gavage followed by measurements of intestinal carbohydrate absorption based on the calculated plasma concentration of $D$-xylose as previously reported, with minor modifications ${ }^{[20]}$. Briefly, after a 12 -h fast, mice were gavaged with $5 \% D$-xylose (SigmaAldrich, Shanghai, China) at dose of $500 \mathrm{mg} / \mathrm{kg}$. The mice were sacrificed $1 \mathrm{~h}$ later and blood samples were promptly collected. Serum $D$-xylose concentrations were measured using a D-xylose assay kit according to the procedures provided by the manufacturer (Nanjing Jiancheng, Nanjing, China).

\section{Fecal bacterial DNA extraction and PCR analysis}

For fecal bacterial DNA extraction, fresh fecal specimens were collected from mice over a $24 \mathrm{~h}$ period. DNA was extracted from $0.5 \mathrm{~g}$ of fecal material using a previously reported method $^{[21]}$. All primers were purchased from Sangon Biotech (Shanghai, China). A standard PCR analysis for A muciniphila was carried out in a 50- $\mu \mathrm{L}$ reaction volume containing $2.5 \mathrm{U}$ of Taq polymerase (Takara, Dalian, China) and $100 \mathrm{ng}$ of DNA template with a denaturation temperature of $94^{\circ} \mathrm{C}$ and using the annealing temperature listed in Table 2 for $60 \mathrm{~s}$ with an extension step at $72^{\circ} \mathrm{C}$, for $28-32$ cycles. Quantitative realtime PCR for Lactobacillus and 16S rRNA was performed on the Applied Biosystems 7900 Fast Real Time PCR system using SYBR Select Master Mix purchased from Life Technol-
Table 2. Primer sequences and annealing temperatures used in this study.

\begin{tabular}{|c|c|c|c|}
\hline Bacteria & & Primer sequence $\left(5^{\prime}\right.$ to $\left.3^{\prime}\right)$ & $\begin{array}{l}\text { Annealing } \\
\text { Temperature }\end{array}$ \\
\hline \multirow[t]{2}{*}{ Lactobacillus } & $\mathrm{F}$ & AGCAGTAGGGAATCTTCCA & $55^{\circ} \mathrm{C}$ \\
\hline & $\mathrm{R}$ & ATTYCACCGCTACACATG & \\
\hline \multirow[t]{2}{*}{ A muciniphila } & $\mathrm{F}$ & CTGAACCAGCCAAGTAGCG & $55^{\circ} \mathrm{C}$ \\
\hline & $\mathrm{R}$ & CCGCAAACTTTCACAACTGACTTA & \\
\hline \multirow[t]{2}{*}{ 16s rRNA } & $\mathrm{F}$ & GCGGTTGTTACAGTCAGATG & $60^{\circ} \mathrm{C}$ \\
\hline & $\mathrm{R}$ & GCCTCAGCGTCAGTATCG & \\
\hline
\end{tabular}

ogy (Shanghai, China) and following the protocol provided by the manufacturer. Cycle threshold values for Lactobacillus and $16 \mathrm{~S}$ rRNA were converted to quantified values based on the standard curves. All individual values are expressed as fold changes compared to the results from LFD-fed mice.

\section{Statistics}

All data are expressed as the mean \pm SEM. Statistical significance was assessed using a paired-sample $t$ test or an analysis of variance, and $P<0.05$ was considered to be statistically significant.

\section{Results \\ Metformin significantly reduces serum LPS levels and gut permeability}

Following 18 weeks of HFD feeding to induce obesity and insulin resistance (impaired IPGTT, data not shown), mice were treated with metformin in their drinking water for another 4 weeks. As shown in Figure 1A, metformin administration did not appear to affect body weight but significantly lowered blood glucose levels in both the intraperitoneal glucose test (IPGTT) and the pyruvate tolerance test (IPPTT) (Figure 1B and 1C). To assess the effect of metformin on endotoxemia, serum LPS levels were measured. We observed that the LPS content of the HFD-fed mice was increased by almost 2-fold compared with that of LFD-fed mice, whereas metformin completely reversed this increase (Figure 1D). To explore mechanisms potentially related to this repressing effect of metformin on LPS, we examined gut permeability via an oral $D$-xylose absorption test and found that serum $D$-xylose concentrations were significantly elevated in HFDfed mice, whereas metformin reduced $D$-xylose concentrations to levels comparable to those of LFD-fed mice (Figure 1E). In agreement with this observation, the tight junction protein, occludin-1, which is important for maintaining the functional integrity of gut mucosa epithelial cells was reduced in both the ileum and the colon of HFD-fed mice whereas metformin clearly reversed this reduction (Figure 1F). Immunofluorescent staining of occludin- 1 in the colon confirmed these findings (Supplementary Figure 1). Furthermore, we extracted 

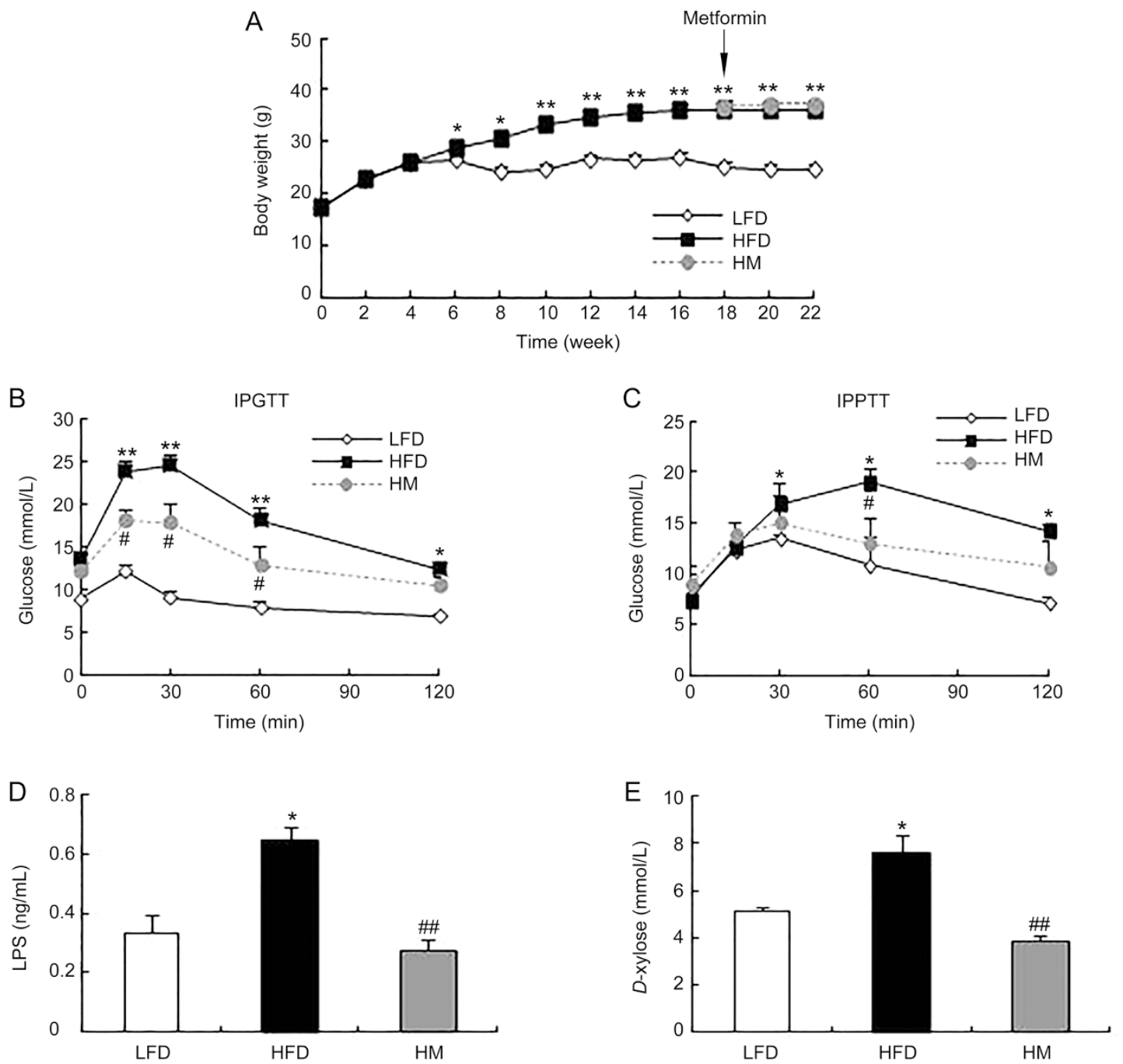

$\mathrm{F}$
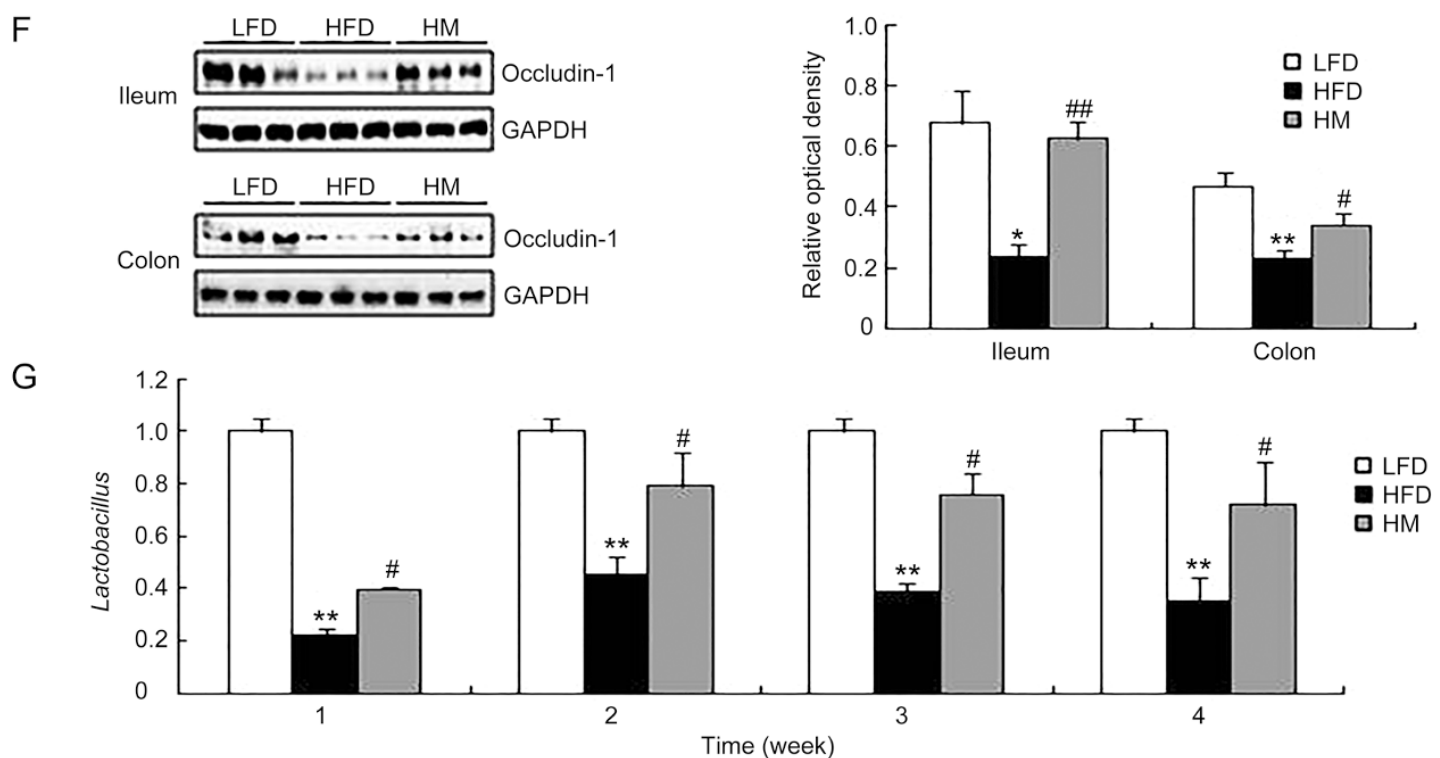

Figure 1. Metformin improves glucose metabolism and attenuates endotoxemia. Mice were fed an LFD or HFD for 18 weeks, and then a set of HFDfed mice were treated with metformin for another 4 weeks. (A) Body weight; (B) Glucose tolerance test (IPGTT); (C) Pyruvate tolerance test (IPPTT); (D) Serum LPS contents; (E) Serum D-xylose contents; (F) Western blot analysis of gut occludin-1 contents; (G) Quantitative real-time PCR analysis of gut lactobacillus. Mean \pm SEM. $n=4-6$. ${ }^{*} P<0.05,{ }^{* *} P<0.01$ vs LFD. ${ }^{\#} P<0.05,{ }^{\# \#} P<0.01$ vs HFD. 
gut bacterial DNA and performed a PCR analysis and found that the abundance of lactobacilli was dramatically reduced in HFD-fed mice, while metformin increased the abundance of this bacteria in as early as one week following metformin intervention. In addition, this effect was more pronounced and lasted over the 4-week intervention period (Figure 1G). Similarly, metformin also restored the reduced abundance of A muciniphila in the feces of HFD-fed mice (data not shown).

\section{Exogenous LPS administration blocks the enhancing effects of metformin on glucose metabolism and insulin signaling}

To further explore whether LPS affects the metformin-mediated insulin-sensitizing action, HFD-fed mice were subcutaneously injected with LPS for $15 \mathrm{~d}$. We observed that exogenous LPS administration (HML group) blocked the glucose-lowering effect of metformin (HM group) in the IPPTT experiment and showed a trend toward elevating glucose levels in the IPGTT experiment (Figure 2A and 2B). The HOMA IR analysis also showed that metformin attenuated the HFD-induced insulin resistance (Figure 2C) and that it also reduced both fasting serum insulin and lipid levels, while LPS administration blocked these beneficial effects of metformin (Table 3 and 4). Neither metformin nor LPS apparently affected the weights of the liver or epididymal fat pads (Figure 2C and 2D). To delineate the underlying signaling mechanism of glucose metabolism, we examined insulin signal transduction and regulatory signaling proteins via Western blot analyses. We

Table 3. Fasting serum insulin level. The mice were fed with LFD or HFD for 18 weeks and then a set of HFD-fed mice were treated without (HM) or with LPS subcutaneous injection (HML) for $5 \mathrm{~d}$ and then continued together with metformin treatment for another $10 \mathrm{~d}$. After $12 \mathrm{~h}$ fasting, serum insulin levels were measured. ${ }^{* *} P<0.01$ vs LFD group. ${ }^{\# \#} P<0.01$ vs HFD group. ${ }^{\$ \$} P<0.01$ vs HM group.

\begin{tabular}{cc}
\hline Group & Serum insulin $(\mu \mathrm{lU} / \mathrm{mL})$ \\
\hline LFD & $10.47 \pm 2.05$ \\
HFD & $22.79 \pm 1.58^{\text {** }}$ \\
HM & $12.91 \pm 1.50^{\# \#}$ \\
HML & $22.41 \pm 1.78^{\$ \$}$ \\
\hline
\end{tabular}

Table 4. Fasting serum lipid level. The mice were fed with LFD or HFD for 18 weeks and then a set of HFD-fed mice were treated without (HM) or with LPS subcutaneous injection (HML) for $5 \mathrm{~d}$ and then continued together with metformin treatment for another $10 \mathrm{~d}$. After $12 \mathrm{~h}$ fasting serum triglyceride (TG), total chelosterol (TC) and free fatty acid (FFA) were measured. Mean \pm SEM. $n=3-6 .{ }^{*} P<0.05,{ }^{* *} P<0.01$ vs LFD. ${ }^{\#} P<0.05$, ${ }^{\# \# P} P<0.01$ vs HFD. ${ }^{\$} P<0.05,{ }^{\$ \$} P<0.01$ vs HM.

\begin{tabular}{llll}
\hline Group & TG $(\mathrm{nmol} / \mathrm{L})$ & TC $(\mathrm{nmol} / \mathrm{L})$ & FFA $(\mathrm{nmol} / \mathrm{L})$ \\
\hline LFD & $2.76 \pm 0.25$ & $1.96 \pm 0.14$ & $1.17 \pm 0.13$ \\
HFD & $4.31 \pm 0.56^{*}$ & $4.56 \pm 0.39^{* *}$ & $2.25 \pm 0.23^{* *}$ \\
HM & $3.18 \pm 0.15^{\#}$ & $3.01 \pm 0.28^{\# \#}$ & $1.41 \pm 0.18^{\#}$ \\
HML & $3.68 \pm 0.75$ & $4.75 \pm 0.56^{\$ \$}$ & $1.66 \pm 0.12^{\$}$ \\
\hline
\end{tabular}

observed that insulin-stimulated PKB Ser473 phosphorylation was enhanced by metformin in both the liver and muscle of HFD-fed mice (HM group), while LPS administration (HML group) blocked this enhancement (Figure 2E and 2F). As a classic functional target of metformin, AMPK T172 phosphorylation was also examined, and we found that the activating effect of metformin on this kinase was clearly inhibited by LPS (HML group) (Figure 2E and 2F). To further explore the effect of LPS on AMPK inhibition, we treated HepG2 cells with different concentrations of LPS and found that LPS not only inhibited AMPK phosphorylation but also inhibited LKB-1 phosphorylation (Supplementary Figure 2). Both inflammatory signaling and endoplasmic reticulum (ER) stress play an inhibitory role on insulin signaling, and we found that metformin treatment increased the level of the inflammation-inhibiting protein IкBa in both the liver and muscle of HFD-fed mice, while LPS reduced the abundance of this protein (Figure $2 \mathrm{~F}$ and $2 \mathrm{G}$ ). In addition, the phosphorylation of the ER stress indicator eIF2a was inhibited by metformin. LPS blocked this effect of metformin in the liver, whereas neither metformin nor LPS had a clear effect on muscular eIF2a phosphorylation (Figure 2F and 2G).

Metformin and LPS exert opposite regulatory effects on redox status, Nrf2 system function and redox-sensitive PTEN expression To examine potential effects of metformin and LPS on redox balance, an indicator of lipid peroxidation, malondialdehyde (MDA) was measured. We observed that MDA levels were elevated in both hepatic and muscular tissues of HFD-fed mice and that they were clearly reduced by metformin intervention, while LPS blocked this reduction (Figure 3A and 3B, left panels). Consistent with these findings, MDA content in the mitochondrial fraction of these tissues was reduced by metformin, whereas it was increased by LPS (Figure $3 \mathrm{~A}$ and 3B, right panels). To further explore whether the Nrf2 system was involved in the redox-regulating effect of metformin, we examined the function of the Nrf2 system by assessing the expression of the NQO-1 protein, which is specifically regulated by Nrf2, and the nuclear Nrf2 content. Both NQO-1 and nuclear Nrf2 contents in hepatic and muscular tissues were increased by metformin, while these effects of metformin were blocked by LPS treatment. Similar effects were observed in Nrf2-regulated HO-1 expression (Figure 3C and 3D).

PTEN is an important protein regulating insulin signaling via PI3K inhibition and is sensitive to redox regulation. To further determine whether redox balance affected PTEN expression, we assessed the PTEN protein content and observed a clear elevation of this protein in the hepatic and muscular tissues of HFD-fed mice, which was inhibited by metformin and increased by LPS (Figure 3C and 3D). To further evaluate the causal relationship of Nrf2-regulated PTEN on insulin signaling, we performed in vitro experiments in HepG2 cells and found that LPS treatment impaired insulinstimulated PKB phosphorylation and also upregulated PTEN expression (supplementary Figure 3). Consistent with these in vivo findings, LPS repressed the Nrf2 system. In particular, 
A
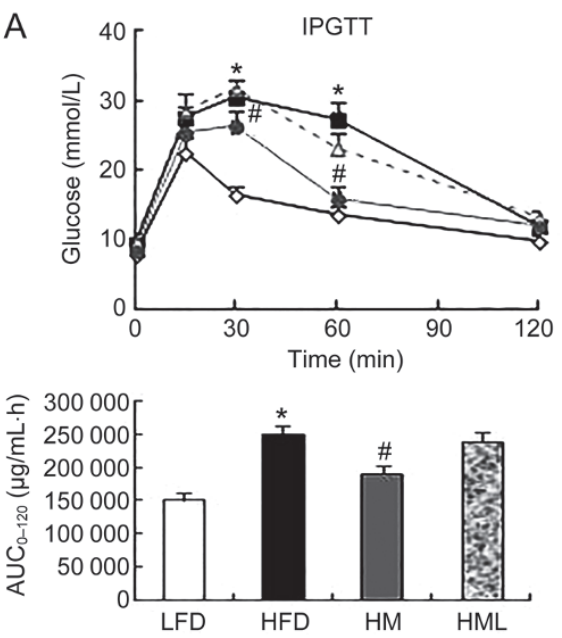

C

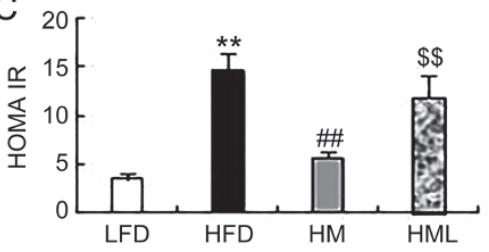

$\mathrm{F}$

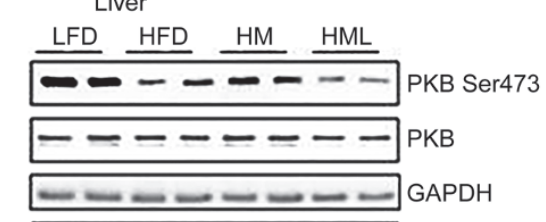

-

트믐-AMPK

- $-\cdots-\cdots$ АМРК

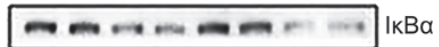

-ニニニニニニ三 ${ }^{p-e l F 2 \alpha}$

-C-CMAPDH

G

Muscle

LFD HFD HM HML

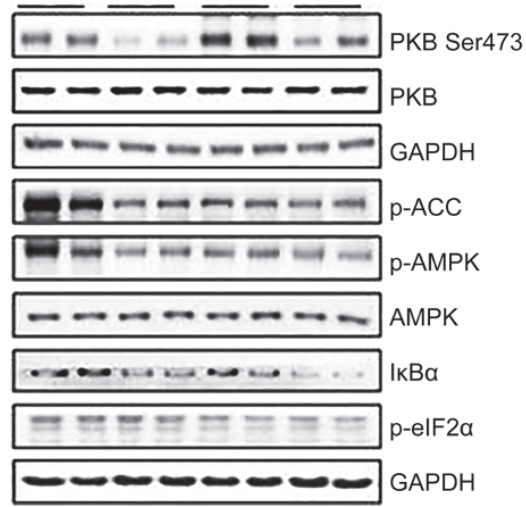

B
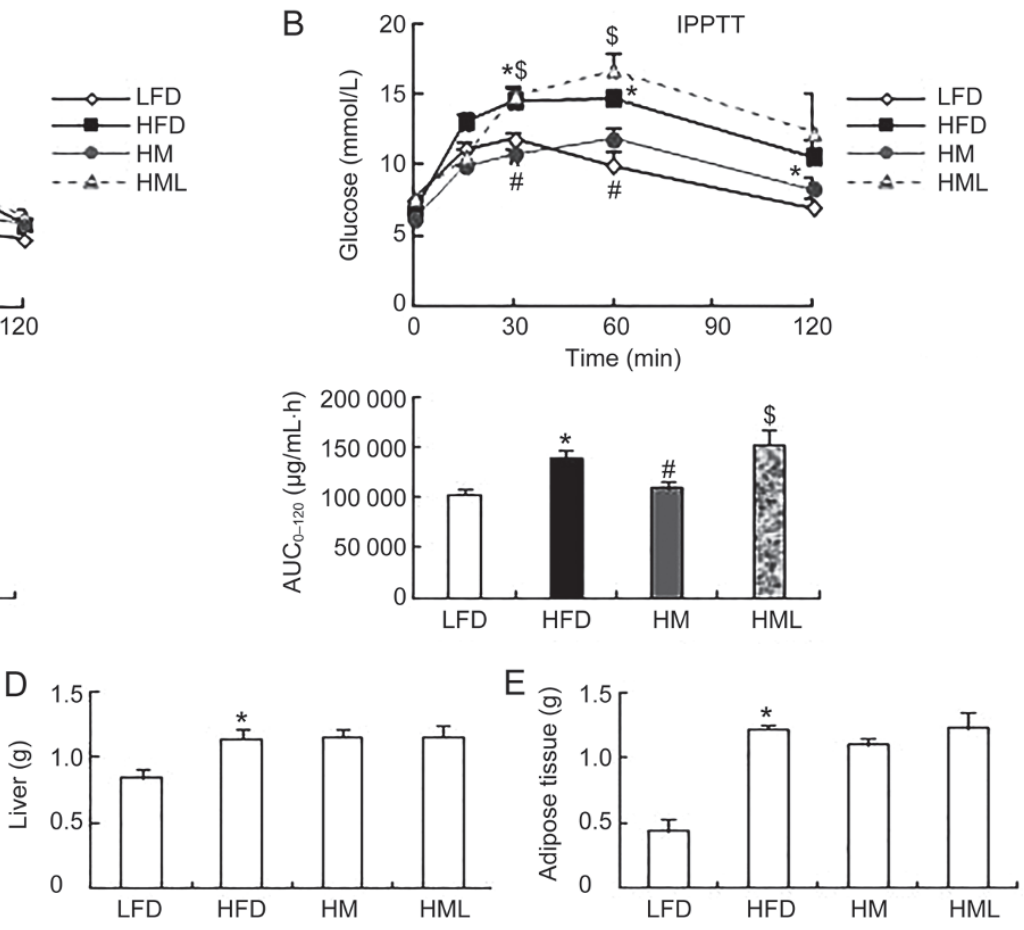

Relative optical density (liver)
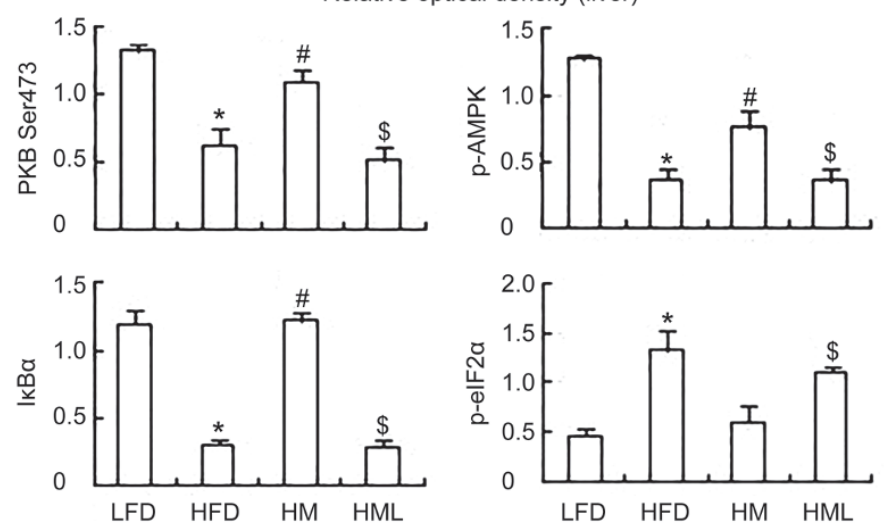

Relative optical density (muscle)
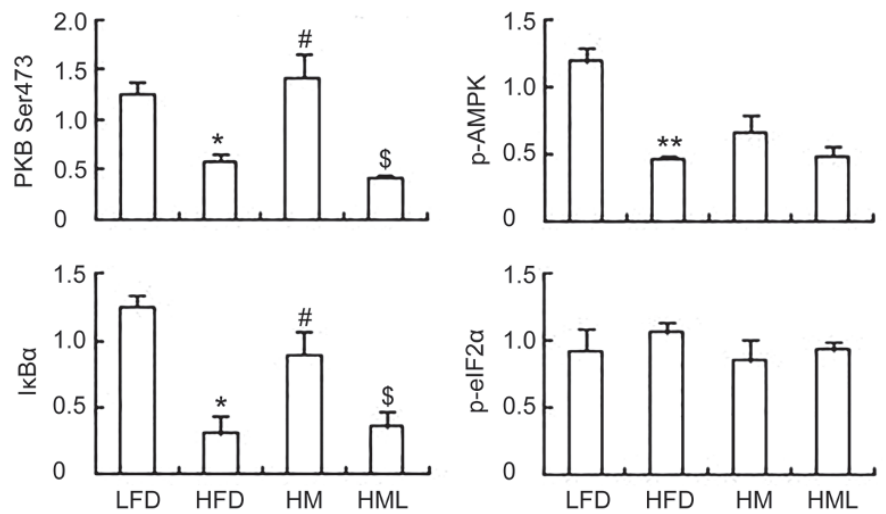

Figure 2. LPS injection blocks the beneficial effects of metformin on glucose metabolism and insulin signaling. The mice were fed an LFD or HFD for 18 weeks, and then a set of HFD-fed mice were treated without (HM) or with a subcutaneous injection of LPS (HML) for $5 \mathrm{~d}$, and then both groups continued to receive metformin treatment for another $10 \mathrm{~d}$. (A) glucose tolerance test (IPGTT); (B) pyruvate tolerance test (IPPTT); (C) HOMA IR; (D) liver weight; (E) weight of epididymal fat pads; Western blot analysis of insulin-stimulated PKB Ser473, AMPK T172, IKB $\alpha$ and $p$-elF2 $\alpha$ levels in the liver (F) or muscle $(G)$, with GAPDH serving as a loading control. Right panels show the protein levels, represented by optical density scanning, corresponding to the left panels. Mean \pm SEM. $n=3-6$. ${ }^{*} P<0.05,{ }^{* *} P<0.01$ vs LFD. ${ }^{\#} P<0.05$, ${ }^{\# \#} P<0.01$ vs HFD. ${ }^{\$} P<0.05$ vs HM. 
A

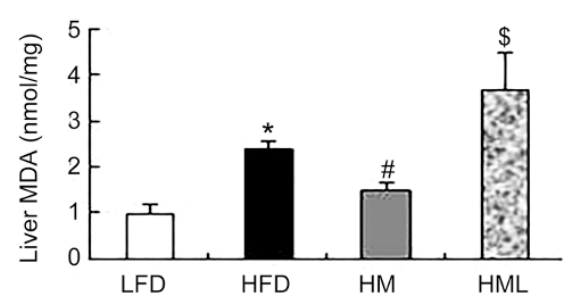

B

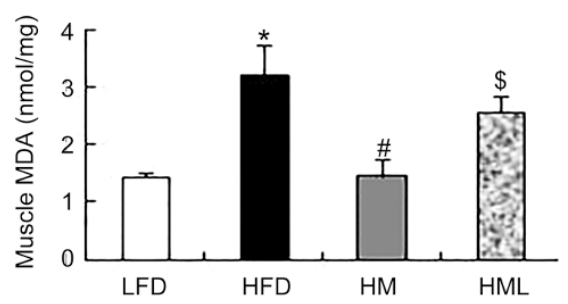

C

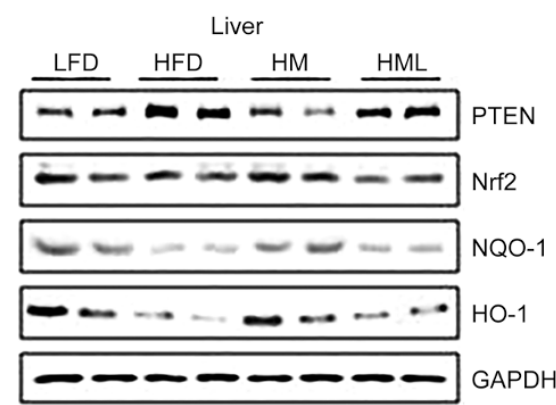

Liver (nuclei)

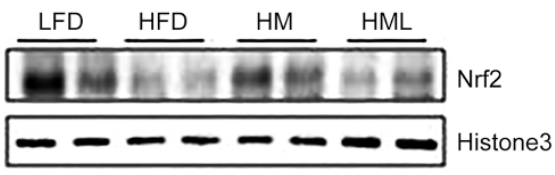

D
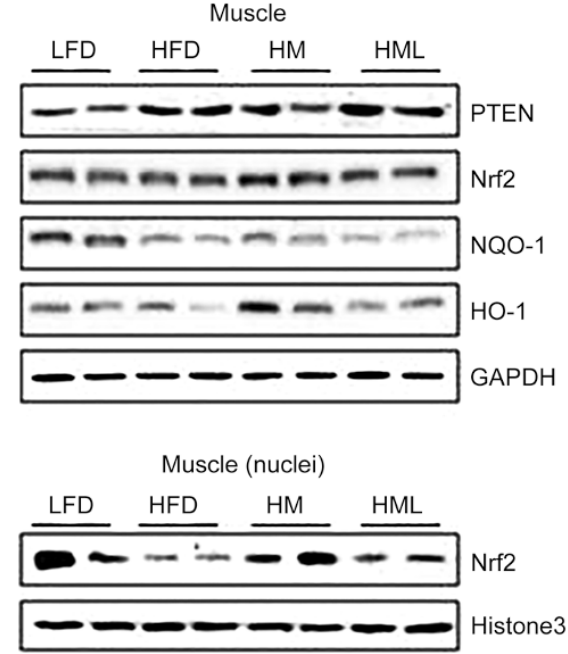
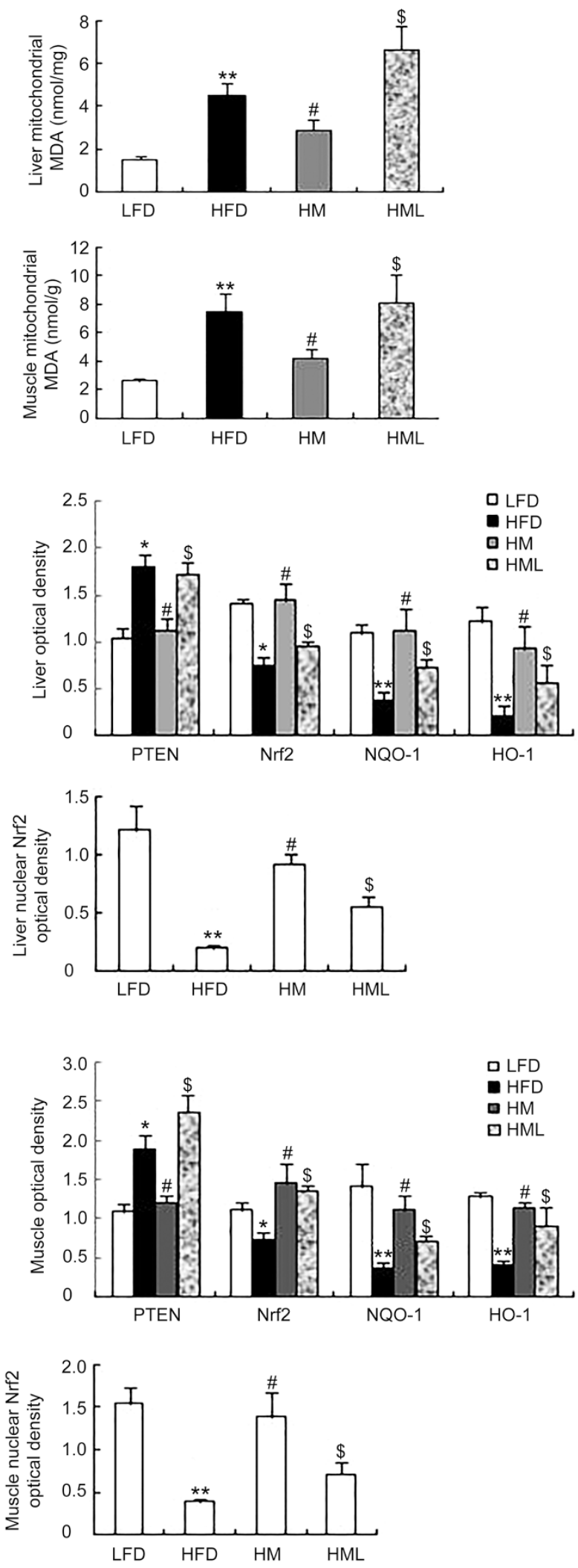

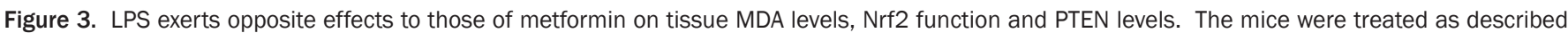

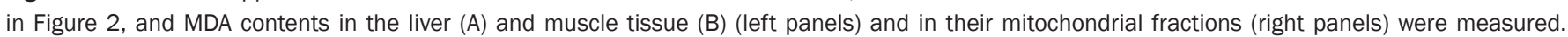

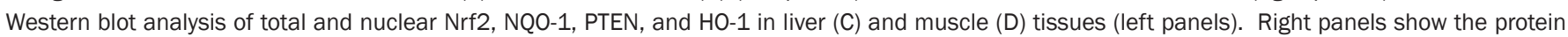

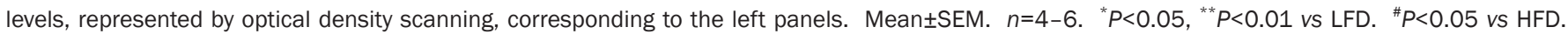
${ }^{\$} \mathrm{P}<0.05$ vs HM. 
the Nrf2 inhibitor retinoic acid blocked the repressive effect of metformin on PTEN, as well as its improvement on PKB phosphorylation (supplementary Figure 3).

\section{Antibiotic treatment improves glucose metabolism and enhances insulin signaling}

To further clarify the role of gut microbiota on insulin action and the relevant signaling alterations, HFD-fed mice were treated with metformin combined with or without a combination of antibiotics. As shown in Figure 4A, the antibiotic treatment (HA group) dramatically reduced blood glucose levels in the IPGTT experiment, while in the combined treatment of antibiotics with metformin (HMA group) blood glucose levels were further reduced. Liver weight was not apparently affected by metformin or/and antibiotics, but the weight of the epididymal fat pads was reduced by the antibiotic treatment (HA group), and it was further reduced when antibiotic treatment was combined with metformin (HMA group) (Figure $4 \mathrm{~B}$ and $4 \mathrm{C}$ ). Insulin-stimulated PKB Ser473 phosphorylation was enhanced by antibiotic treatment (HA group, Figure 4D and $4 \mathrm{E})$. Interestingly, AMPK phosphorylation was enhanced by antibiotic treatment (HA group), and in combination with metformin treatment (HMA group), AMPK phosphorylation was further enhanced. In addition, antibiotic treatment (HA group) increased IKBa protein content and reduced eIF2a phosphorylation in the liver (Figure 4D and 4E).

\section{Antibiotic treatment exerts effects similar to those of metformin on reducing oxidative stress, activating the Nrf2 system and repressing PTEN expression}

To identify whether modulating gut microbiota affects redox balance, the Nrf2 system and PTEN expression, we measured MDA levels and found that MDA contents in the liver and muscle tissues and in their mitochondrial factions were reduced following antibiotic treatment (HA group) (Figure $5 \mathrm{~A}$ and 5B). Furthermore, Nrf2 function, as assessed on the nuclear Nrf2 content and the abundance of its regulatory target HO-1, was enhanced by antibiotic treatment. In combination with metformin (HMA group), Nrf2 system function was further activated (Figure 5C and D). In contrast, PTEN contents were reduced in both liver and muscle tissues following the antibiotic treatment (HA group), while its combination with metformin further reduced PTEN content (Figure 5C and 5D). We also assessed gut occludin-1 content via Western blot analysis and found that the antibiotic treatment enhanced occludin-1 abundance in both the ileum and the colon (data not shown).

\section{Discussion}

The modulation of gut microbiota as a part of the underlying mechanism for the glucose-lowering effect of metformin has been suggested by several studies. Metformin has been shown to influence the metabolite production of gut bacteria and nutrition absorption, affecting energy homeostasis ${ }^{[22,23]}$. In addition, metformin increases blood levels of GLP-1, an insulin sensitizing hormone, by promoting its secretion through a gut bacteria-related mechanism ${ }^{[15]}$. Metformin has also been shown to upregulate certain probiotics, such as A muciniphila and lactobacillus, and importantly, this modulation was associated with the beneficial effects of metformin on gut barrier function and glucose metabolism ${ }^{[14,16]}$. Because metformin modulates the composition of gut bacteria and enhances gut barrier function, we inferred that the alteration of the gut bacteria community by metformin may reduce LPS absorption by reducing its absorption via protecting gut integrity. In support of this, feeding a HFD to mice was found to increase gut gram-negative bacteria, which was shown to be correlated to endotoxemia and insulin resistance. Particularly, polymyxin B treatment, an antibiotic specific for gram-negative bacteria, lowered LPS levels and improved hepatic steatosis ${ }^{[24,25]}$. As gut-derived LPS is a major source of endotoxemia, which contributes to chronic low-grade inflammation, this reduction by metformin on blood LPS levels could be a novel mechanism for the metformin-mediated insulin-sensitizing effects. In this study, we indeed detected a dramatic effect of metformin on lowering blood LPS levels and protecting gut barrier function in HFD-fed mice. In addition, we observed that administering exogenous LPS to the mice blocked the improvements of metformin on insulin signaling and glucose tolerance, while antibiotic treatment showed opposite effects to those of LPS. These findings suggest a previously unrecognized role of metformin in modulating gut bacteria and blood LPS levels in its insulin signal-enhancing and glucose-lowering effects.

The most important question regarding the underlying pharmacological mechanism by which metformin acts is how it activates AMPK. It has been shown that metformin activates AMPK through LKB1 because LKB1 is the up-stream kinase regulating the phosphorylation of the AMPK catalytic a subunit at T172, a crucial phosphorylation site for AMPK activity $^{[26]}$. Alternatively, it has been proposed that metformin activates AMPK via inhibiting mitochondrial complex 1 and consequently increasing the ADP/ATP ratio, a basic stimulating factor for AMPK activity ${ }^{[27,28]}$. In this study, we observed that AMPK phosphorylation was apparently inhibited by LPS administration, especially in the liver, a major tissue target for the glucose-lowering effect of metformin. This work provides an additional pathway by which metformin activates AMPK through reducing endotoxemia-mediated inhibition in HFDfed mice. In agreement with these finding, other studies have indicated that LPS can lead to an inhibition of AMPK activity $^{[29,30]}$. Furthermore, we revealed that in cultured hepatic HepG2 cells, LPS reduced AMPK activation through LKB inhibition.

The interaction of LPS with metformin in altering insulin signaling was further investigated in this study. We observed that LPS administration attenuated the metforminmediated inhibition on inflammatory signaling, which affects the sensitizing-effect of metformin on insulin signaling. We also showed that metformin inhibited the LPS-mediated IKBa reduction (Supplementary Figure 3). Therefore, the relative concentrations of LPS and metformin in different experimental conditions may determine the final effect of metformin on 
A

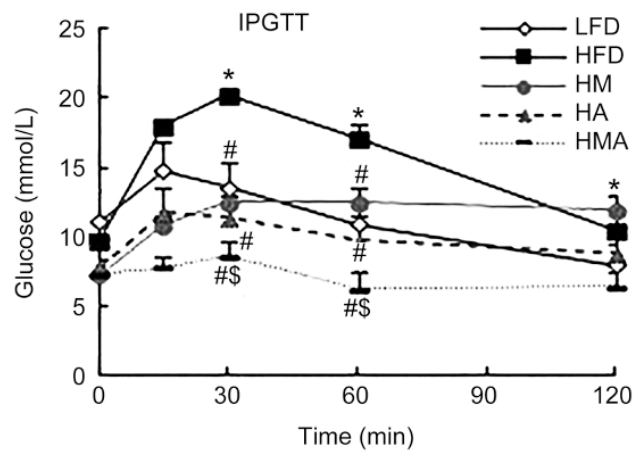

B

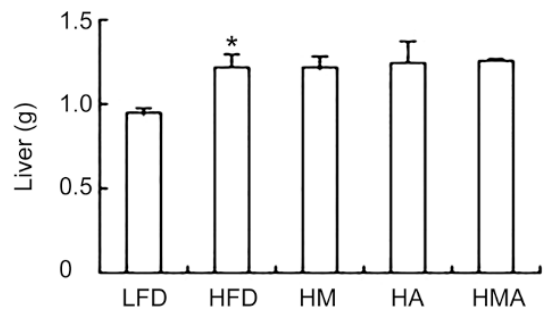

D

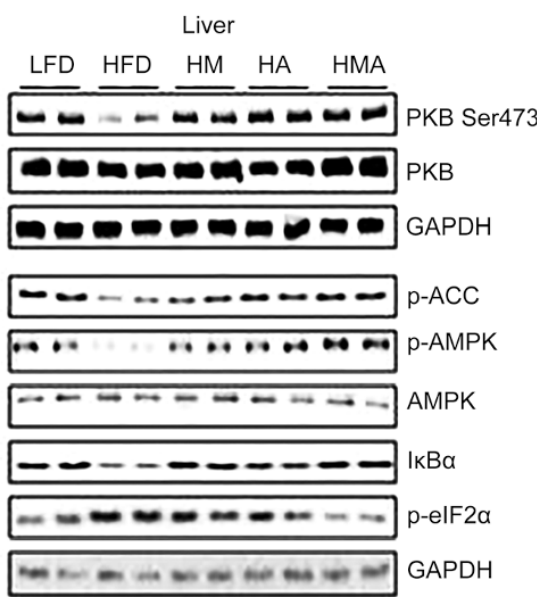

E

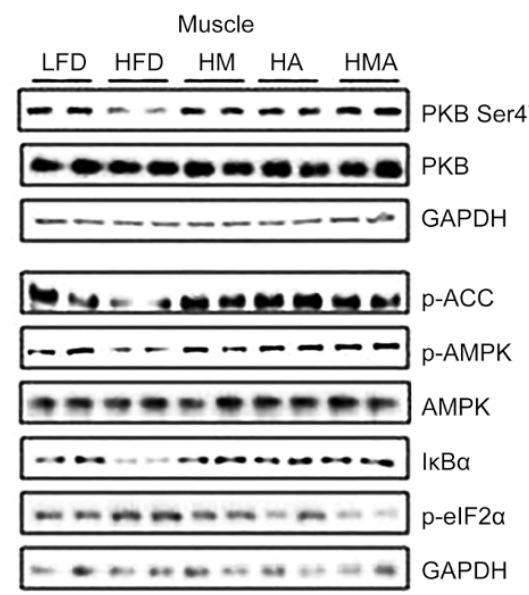

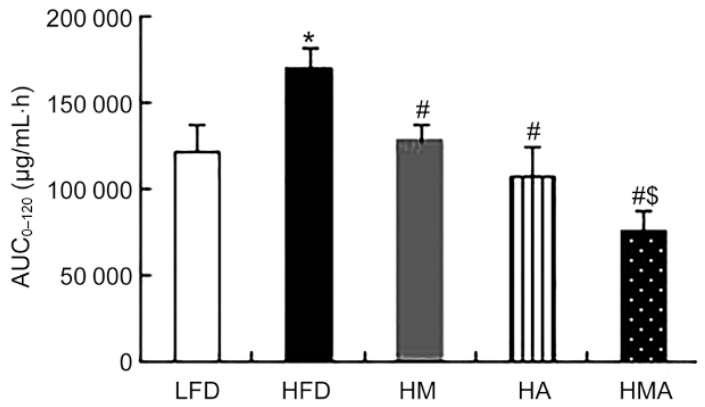

C

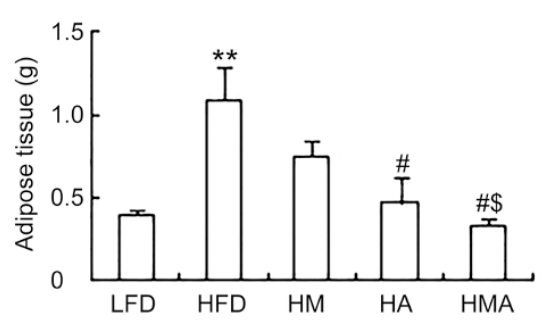

Relative optical density (liver)
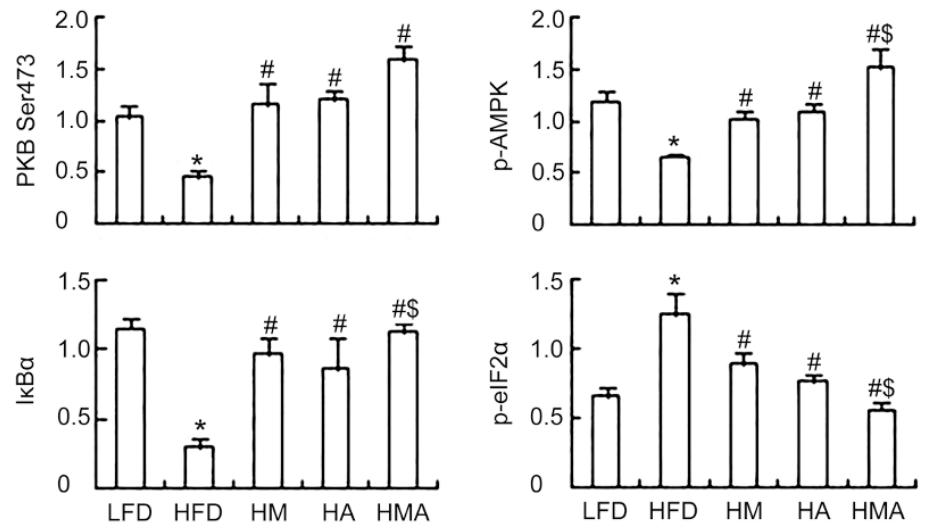

Relative optical density (muscle)
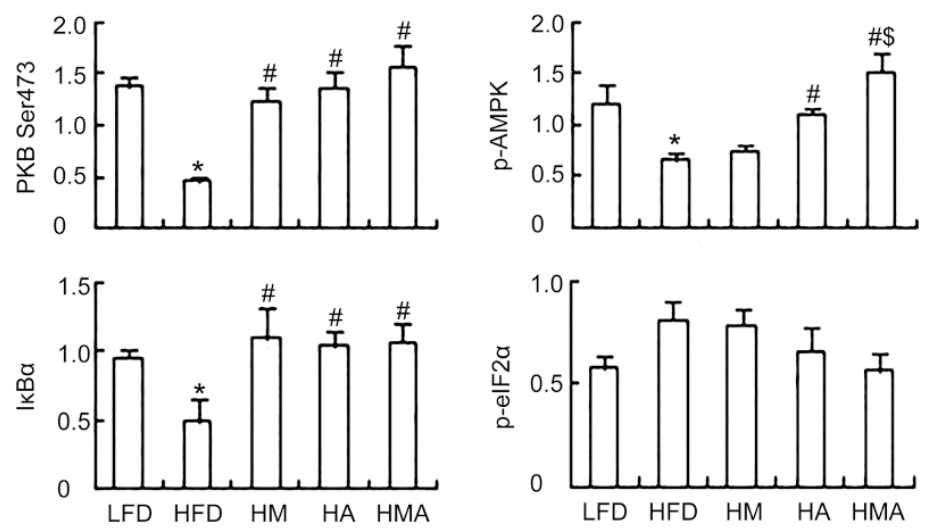

Figure 4. Antibiotic treatment has similar effects to those of metformin in improving glucose metabolism and insulin signaling. The mice were fed an LFD or HFD for 18 weeks, and then a set of HFD-fed mice were treated with a combination of antibiotics for another $7 \mathrm{~d}$ and then continually treated without (HA) or with metformin (HMA) in their drinking water for 4 weeks. (A) Glucose tolerance test (IPGTT); (B) Liver weight; (C) Weight of epididymal fat pads; Western blot analysis of insulin-stimulated PKB Ser473, AMPK T172, IKB $\alpha$ and p-elF2 $\alpha$ levels in the liver (D) and muscle (E), with GAPDH serving as a loading control. Right panels show the protein levels, represented by optical density scanning, corresponding to the left panels. Mean $\pm S E M$. $n=4-6$. ${ }^{*} P<0.05,{ }^{* *} P<0.01$ vs LFD. ${ }^{\#} P<0.05$ vs HFD. ${ }^{\$} P<0.05$ vs HM. 
A

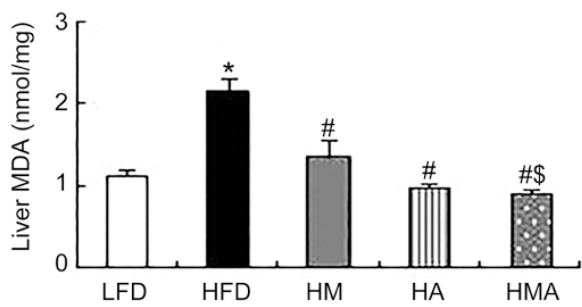

B

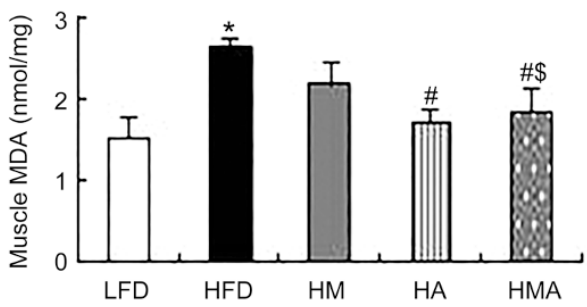

C

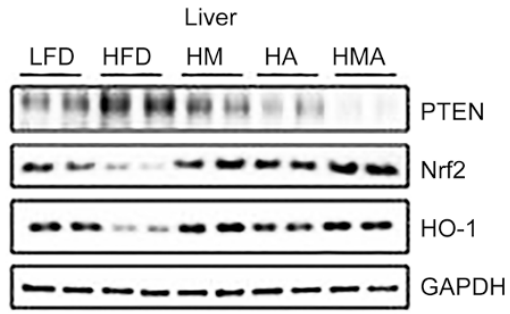

Liver (nuclei)

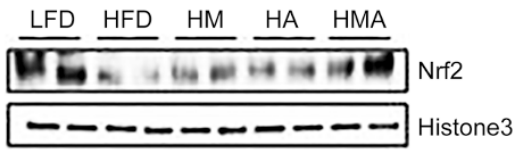

D

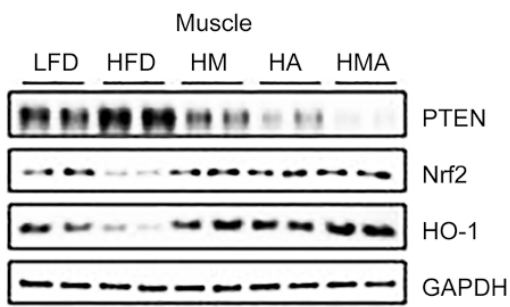

Muscle (nuclei)

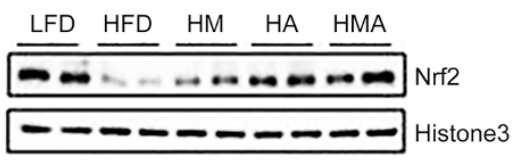

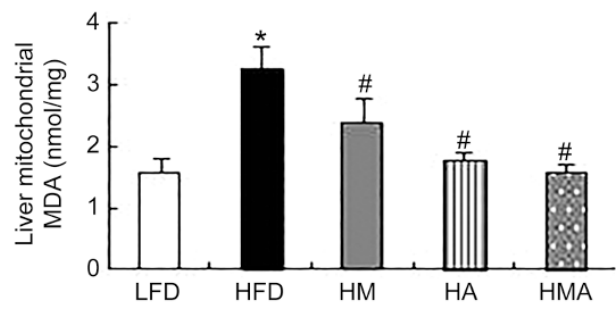
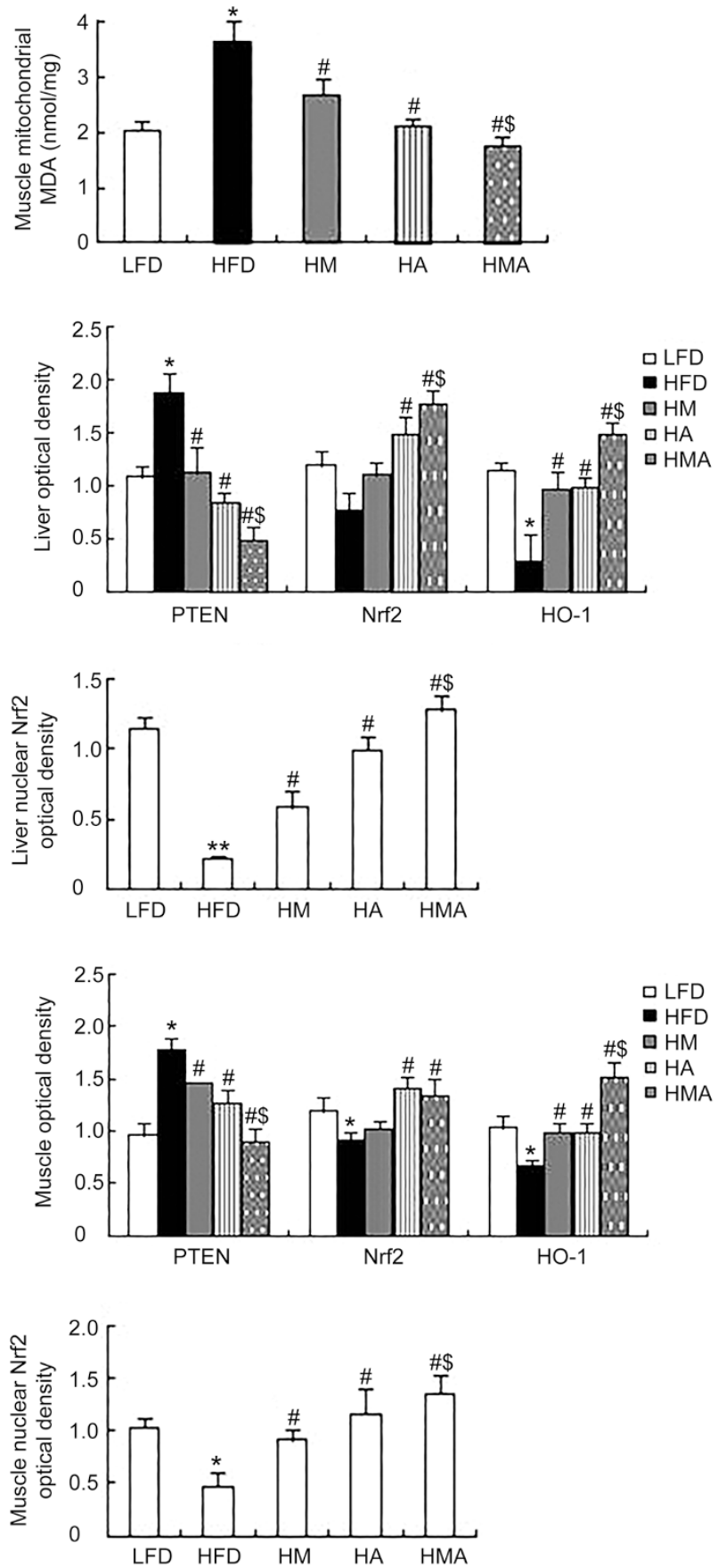

Figure 5. Antibiotic treatment shows similar effects to those of metformin in reducing MDA levels, activating Nrf2 function and repressing PTEN expression in the liver and muscle. The mice were treated as described in Figure 4 and the MDA contents in the liver (A) and muscle tissue (B) (left panels) and in their mitochondrial fractions (right panels) were measured. Western blot analysis of PTEN, total and nuclear Nrf2 and HO-1 in liver (C) and muscle (D) tissues (left panels). Right panels show the protein levels, represented by optical density scanning, corresponding to the left panels. Mean \pm SEM. $n=4-6$. ${ }^{*} P<0.05,{ }^{* *} P<0.01$ vs LFD. ${ }^{\#} P<0.05$ vs HFD. ${ }^{\$} P<0.05$ vs HM. 
inflammation. In addition to their interaction in inflammatory signaling, a previous report has shown that LPS upregulates PTEN expression ${ }^{[31]}$, and PTEN is important for the negative regulation of PI3K activity, an upstream signaling component of PKB ${ }^{[32,33]}$. We assessed PTEN abundance and found that LPS clearly increased its expression in both skeletal muscle and the liver, while metformin reduced its expression. These data therefore suggest PTEN as a potentially significant target for the interaction of LPS with metformin, in addition to AMPK and inflammation, in regulating insulin sensitivity.

Because oxidative stress could be affected by inflammatory status ${ }^{[7]}$, we assessed redox balance by measuring tissue MDA levels and found that metformin and LPS played opposite roles in affecting redox balance. Particularly, we identified Nrf2 as an important regulating target for redox balance. We clearly showed that metformin upregulated the Nrf2 system, while LPS treatment downregulated the Nrf2 system in both HFD-fed mice and HepG2 cells (Figure 3C and 3D, Supplementary Figure 2 and 3). These results are in line with previous reports showing the interactions of the effects of metformin and LPS on the Nrf2 system ${ }^{[34,35]}$. The underlying regulatory mechanisms of LPS on the Nrf2 system were not addressed in the current study. Tomasi et al reported that LPS, through reducing the sumoylation of Nrf2, affected its promoting function on anti-oxidant enzyme transcription ${ }^{[36]}$. We observed that LPS affected total Nrf2 protein content, indicating a different regulatory mechanism of LPS on the Nrf2 system in our experimental setting. Because LPS is reported to promote proteasome-degrading function ${ }^{[37]}$, Nrf2 turnover may be accelerated by LPS. There is also a report showing that PTEN promotes Nrf2 phosphorylation-dependent degradation ${ }^{[34]}$, and therefore, LPS could promote Nrf2 degradation by upregulating PTEN expression. Interestingly, metformin has been shown to inhibit LPS-evoked inflammatory signaling through regulating ATF- $3^{[38,39]}$ and has been recently found to activate Nrf2 to inhibit the inflammation response ${ }^{[35]}$. Whatever the specific mechanism involved, our data suggest that LPS-triggered Nrf2 dysfunction and the loss of redox balance could contribute to its detrimental effect on metformin and insulin action.

The reciprocal regulation between Nrf2 system function and PTEN expression has been suggested by several studies ${ }^{[34,40]}$. In this study, by using an Nrf2 inhibitor, we found that Nrf2 is causally involved in the effect of metformin on the regulation of PTEN and insulin signaling (Supplementary Figure 3). Therefore, the interaction of LPS with metformin in the Nrf2/ PTEN/PKB pathway is involved in their regulation of insulin sensitivity. Whether this mechanism also operates in other models of insulin-resistant and diabetic conditions, particularly in patients, is very interesting and deserves further investigation.

In concert with the role of gut bacteria and LPS on the regulation of host inflammation and insulin sensitivity, antibiotic treatment aiming to reduce gut-derived LPS $^{[19]}$ exerted similar effects to metformin in attenuating oxidative stress, activating the Nrf2 system and reducing PTEN expression. In addi- tion, as previously reported ${ }^{[19]}$, we also observed a systemic repression of inflammation by antibiotic treatment. A striking observation in this study was that antibiotic treatment exerted a dramatic effect in improving glucose intolerance in HFD-fed mice, which was comparable to that of metformin. It might therefore be promising to develop a proper set of probiotics for more effective therapeutic interventions in treating diabetes ${ }^{[41]}$. In this study, we also noticed that the effects of antibiotic treatment on IPGTT and several other processes, including AMPK activation, were additive to the effects of metformin, suggesting that metformin only partially operates by modulating gut bacteria to affect insulin sensitivity in additional to its direct activation of AMPK in insulin-sensitive target tissues.

In summary, three major and novel findings are suggested by this study: 1) The attenuation of endotoxemia is related to the therapeutic efficacy of metformin in improving insulin resistance. 2) Metformin inhibits inflammatory signaling and stimulates AMPK activity in insulin-sensitive tissue, which is relevant to its alleviation of endotoxemia. 3) Metformin and LPS play opposite roles in regulating the Nrf2 anti-oxidative system, which may be important for PTEN expression and its regulation of insulin signaling.

\section{Acknowledgements}

This work was supported by a National Natural Science Foundation of China (№ 81270886 to Zhi-wen YU).

\section{Author contribution}

Zhi-wen YU designed the study. Zi-yu ZHOU, Li-wei REN, Ping ZHAN, Han-yan YANG, and Dan-dan CHAI conducted the experiments. Zi-yu ZHOU, Li-wei REN, and Zhi-wen YU analyzed data. Zi-yu ZHOU and Zhi-wen YU wrote the manuscript.

\section{Supplementary information}

Supplementary Figures are available at the Acta Pharmacologica Sinica's website.

\section{References}

1 Reaven GM. Pathophysiology of insulin resistance in human disease. Physiol Rev 1995; 75: 473-86.

2 Backhed F, Manchester JK, Semenkovich CF, Gordon Jl. Mechanisms underlying the resistance to diet-induced obesity in germ-free mice. Proc Natl Acad Sci U S A 2007; 104: 979-84.

3 Bradlow HL. Obesity and the gut microbiome: pathophysiological aspects. Horm Mol Biol Clin Investig 2014; 17: 53-61.

4 Udayappan SD, Hartstra AV, Dallinga-Thie GM, Nieuwdorp M. Intestinal microbiota and faecal transplantation as treatment modality for insulin resistance and type 2 diabetes mellitus. Clin Exp Immunol 2014; 177: 24-9.

5 Ramakrishna BS. Role of the gut microbiota in human nutrition and metabolism. J Gastroenterol Hepatol 2013; 28 Suppl 4: 9-17.

6 Prajapati B, Jena PK, Rajput P, Purandhar K, Seshadri S. Understanding and modulating the Toll like Receptors (TLRs) and NOD like receptors (NLRs) cross talk in type 2 diabetes. Curr Diabetes Rev 2014; 10: 190-200.

7 Houstis N, Rosen ED, Lander ES. Reactive oxygen species have a 
causal role in multiple forms of insulin resistance. Nature 2006; 440: 944-8.

8 Uruno A, Yagishita Y, Yamamoto M. The Keap1-Nrf2 system and diabetes mellitus. Arch Biochem Biophys 2015; 566: 76-84.

9 He HJ, Wang GY, Gao Y, Ling WH, Yu ZW, Jin TR. Curcumin attenuates Nrf2 signaling defect, oxidative stress in muscle and glucose intolerance in high fat diet-fed mice. World J Diabetes 2012; 3: 94104.

10 Yu Z, Shao W, Chiang Y, Foltz W, Zhang Z, Ling W, et al. Oltipraz upregulates the nuclear factor (erythroid-derived 2)-like 2 [corrected] (NRF2) antioxidant system and prevents insulin resistance and obesity induced by a high-fat diet in C57BL/6J mice. Diabetologia 2011; 54: 922-34.

11 Yang Y, Li W, Li Y, Wang Q, Gao L, Zhao J. Dietary Lycium barbarum polysaccharide induces Nrf2/ARE pathway and ameliorates insulin resistance induced by high-fat via activation of PI3K/AKT signaling. Oxid Med Cell Longevity 2014; 2014: 145641. Epub 2014 Jun 22.

12 Cheng AS, Cheng YH, Chiou CH, Chang TL. Resveratrol upregulates Nrf2 expression to attenuate methylglyoxal-induced insulin resistance in Hep G2 cells. J Agric Food Chem 2012; 60: 9180-7.

13 Tan Y, Ichikawa T, Li J, Si Q, Yang H, Chen X, et al. Diabetic downregulation of Nrf2 activity via ERK contributes to oxidative stressinduced insulin resistance in cardiac cells in vitro and in vivo. Diabetes 2011; 60: 625-33.

14 Lee H, Ko G. Effect of metformin on metabolic improvement and gut microbiota. Appl Environ Microbiol 2014; 80: 5935-43.

15 Napolitano A, Miller S, Nicholls AW, Baker D, Van Horn S, Thomas E, et al. Novel gut-based pharmacology of metformin in patients with type 2 diabetes mellitus. PLoS One 2014; 9: e100778. eCollection 2014.

16 Shin NR, Lee JC, Lee HY, Kim MS, Whon TW, Lee MS, et al. An increase in the Akkermansia spp population induced by metformin treatment improves glucose homeostasis in diet-induced obese mice. Gut 2014; 63: 727-35.

17 Everard A, Belzer C, Geurts L, Ouwerkerk JP, Druart C, Bindels LB, et al. Cross-talk between Akkermansia muciniphila and intestinal epithelium controls diet-induced obesity. Proc Natl Acad Sci U S A 2013; 110: 9066-71.

18 Moreira AP, Texeira TF, Ferreira AB, Peluzio MC, Alfenas RC. Influence of a high-fat diet on gut microbiota, intestinal permeability and metabolic endotoxaemia. Br J Nutr 2012; 108: 801-9.

19 Carvalho BM, Guadagnini D, Tsukumo DM, Schenka AA, Latuf-Filho P, Vassallo J, et al. Modulation of gut microbiota by antibiotics improves insulin signalling in high-fat fed mice. Diabetologia 2012; 55: 282334.

20 Shalaby MA, Latif HA, Sayed ME. Interaction of insulin with prokinetic drugs in STZ-induced diabetic mice. World J Gastrointest Pharmacol Ther 2013; 4: 28-38.

21 Yu Z, Morrison M. Improved extraction of PCR-quality community DNA from digesta and fecal samples. Biotechniques 2004; 36: 808-12.

22 Cabreiro F, Gems D. Worms need microbes too: microbiota, health and aging in Caenorhabditis elegans. EMBO Mol Med 2013; 5: 1300-10.

23 Cabreiro F, Au C, Leung KY, Vergara-Irigaray N, Cocheme HM, Noori T, et al. Metformin retards aging in $\mathrm{C}$ elegans by altering microbial folate and methionine metabolism. Cell 2013; 153: 228-39.

24 Cani PD, Amar J, Iglesias MA, Poggi M, Knauf C, Bastelica D, et al. Metabolic endotoxemia initiates obesity and insulin resistance. Diabetes 2007; 56: 1761-72.

25 Pappo I, Becovier H, Berry EM, Freund HR. Polymyxin B reduces cecal flora, TNF production and hepatic steatosis during total parenteral nutrition in the rat. J Surg Res 1991; 51: 106-12.

26 Shaw RJ, Lamia KA, Vasquez D, Koo SH, Bardeesy N, Depinho RA, et al. The kinase LKB1 mediates glucose homeostasis in liver and therapeutic effects of metformin. Science 2005; 310: 1642-6.

27 Foretz M, Hebrard S, Leclerc J, Zarrinpashneh E, Soty M, Mithieux G, et al. Metformin inhibits hepatic gluconeogenesis in mice independently of the LKB1/AMPK pathway via a decrease in hepatic energy state. J Clin Invest 2010; 120: 2355-69.

28 Stephenne X, Foretz M, Taleux N, van der Zon GC, Sokal E, Hue $\mathrm{L}$, et al. Metformin activates AMP-activated protein kinase in primary human hepatocytes by decreasing cellular energy status. Diabetologia 2011; 54: 3101-10.

29 Tadie JM, Bae HB, Deshane JS, Bell CP, Lazarowski ER, Chaplin DD, et al. Toll-like receptor 4 engagement inhibits adenosine 5'-monophosphate-activated protein kinase activation through a high mobility group box 1 protein-dependent mechanism. Mol Med 2012; 18: 659-68.

30 Wang L, Li L, Ran X, Long M, Zhang M, Tao Y, et al. Lipopolysaccharides reduce adipogenesis in 3T3-L1 adipocytes through activation of NF-kappaB pathway and downregulation of AMPK expression. Cardiovasc Toxicol 2013; 13: 338-46.

31 Okamura H, Yoshida K, Sasaki E, Qiu L, Amorim BR, Morimoto H, et al. Expression of PTEN and Akt phosphorylation in lipopolysaccharidetreated NIH3T3 cells. Cell Biol Int 2007; 31: 119-25.

32 Hou R, Zhang J, Yin T, Cao H, Zhang N, Li X, et al. Upregulation of PTEN by peroxynitrite contributes to cytokine-induced apoptosis in pancreatic beta-cells. Apoptosis 2010; 15: 877-86.

33 Song $\mathrm{P}, \mathrm{Wu} \mathrm{Y}, \mathrm{Xu} J$, Xie Z, Dong $\mathrm{Y}$, Zhang $\mathrm{M}$, et al. Reactive nitrogen species induced by hyperglycemia suppresses Akt signaling and triggers apoptosis by upregulating phosphatase PTEN (phosphatase and tensin homologue deleted on chromosome 10) in an LKB1dependent manner. Circulation 2007; 116: 1585-95.

34 Rojo Al, Rada P, Mendiola M, Ortega-Molina A, Wojdyla K, RogowskaWrzesinska $A$, et al. The PTEN/NRF2 axis promotes human carcinogenesis. Antioxid Redox Signal 2014; 21: 2498-514.

35 Ashabi G, Khalaj L, Khodagholi F, Goudarzvand M, Sarkaki A. Pretreatment with metformin activates Nrf2 antioxidant pathways and inhibits inflammatory responses through induction of AMPK after transient global cerebral ischemia. Metab Brain Disease 2015; (3): 747-54.

36 Tomasi ML, Ryoo M, Yang H, Iglesias AA, Ko KS, Lu SC. Molecular mechanisms of lipopolysaccharide-mediated inhibition of glutathione synthesis in mice. Free Radic Biol Med 2014; 68: 148-58.

37 Dhungana S, Merrick BA, Tomer KB, Fessler MB. Quantitative proteomics analysis of macrophage rafts reveals compartmentalized activation of the proteasome and of proteasome-mediated ERK activation in response to lipopolysaccharide. Mol Cell Proteomics 2009; 8: 201-13.

38 Rao J, Qian X, Li G, Pan X, Zhang C, Zhang F, et al. ATF3-mediated NRF2/HO-1 signaling regulates TLR4 innate immune responses in mouse liver ischemia/reperfusion injury. Am J Transplant 2015; 15: 76-87.

39 Kim J, Kwak HJ, Cha JY, Jeong YS, Rhee SD, Kim KR, et al. Metformin suppresses lipopolysaccharide (LPS)-induced inflammatory response in murine macrophages via activating transcription factor-3 (ATF-3) induction. J Biol Chem 2014; 289: 23246-55.

40 Thimmulappa RK, Scollick C, Traore K, Yates M, Trush MA, Liby KT, et al. Nrf2-dependent protection from LPS induced inflammatory response and mortality by CDDO-imidazolide. Biochem Biophys Res Commun 2006; 351: 883-9.

41 Carvalho BM, Saad MJ. Influence of gut microbiota on subclinical inflammation and insulin resistance. Mediators Inflamm 2013; 2013: 986734. 